\title{
Pelatihan Pengetikan 5 Jari pada Microsoft Word untuk Persiapan AKM Siswa kelas 5 MI Darussalam Karanganyar Pagerbarang Tegal
}

\author{
5 Finger Typing Training in Microsoft Word for AKM Preparation 5th grade students \\ of MI Darussalam Karanganyar \\ Nurul Desy Fitria Rahman', Moh. Toharudin ${ }^{2}$ \\ ${ }_{1,2}$ Pendidikan Guru Sekolah Dasar, Fakultas Keguruan dan Ilmu Pendidikan, Universitas Muhadi \\ Setiabudi, Indonesia \\ e-mail: ${ }^{1}$ nuruldesy01@gmail.com, ${ }^{2}$ sunantoha12@gmail.com
}

\begin{abstract}
Abstrak
Menteri Pendidikan dan Kebudayaan Nadiem Anwar Makarim menerbitkan Surat Edaran (SE) Nomor 1 Tahun 2021 tentang Pelaksanaan Ujian Sekolah, Peniadaan Ujian Nasional (UN) dan Ujian Kesetaraan Tahun Pelajaran 2020/2021. Surat Edaran yang diterbitkan pada Februari 2021 ini ditujukan kepada seluruh Gubernur, Bupati dan Walikota di seluruh Indonesia. Adapun ujian yang digunakan tahun ini adalah Asesmen Kompetensi Minimum (AKM). Pelaksanaan AKM juga dilaksanakan oleh SD/MI. Dalam menghadapi AKM maka siswa siswi MI Darussalam Karanganyar harus bisa mengoperasikan Komputer/Laptop untuk dapat menjawab soal-soal AKM, Karena soal AKM berbasis Online dan siswa siswi MI belum pada bisa menggunakan Laptop/Komputer. Oleh karena itu Mahasiswa mengadakan Pelatihan dan Simulasi kepada siswa siswi kelas 5 MI Darussalam yang akan menghadapi AKM. Tujuan dari pelatihan dan simulasi ini yaitu untuk melatih siswa siswi supaya bisa menggunakan Laptop begitu juga mengetahui Microsoft Word dan cara pengetikan 5 Jari, karena hal ini adalah modal yang paling utama supaya siswa siswi kedepanya bisa mengerjakan soal-soal AKM. Metode yang digunakan yaitu Pelatihan dan Simulasi. Hasil yang dapat diperoleh dari adanya pelatihan ini yaitu siswa siswi dapat mengoperasikan Laptop, Cara Login AKM, Menjawab soal AKM, Mengetik 5 jari dan mengetahui fungsi tombol keyboard dan Toolbar Microsoft Word. Selain itu mendapatkan nilai rasa ingin terus belajar, jujur, semangat, komunikatif, menarik.
\end{abstract}

Kata kunci :Pengetikan, Microsoft Word, AKM

\begin{abstract}
Minister of Education and Culture Nadiem Anwar Makarim issued Circular Letter (SE) Number 1 of 2021 concerning Implementation of School Exams, Elimination of National Examinations (UN) and Equivalence Exams for the 2020/2021 Academic Year. This Circular issued in February 2021 is addressed to all Governors, Regents and Mayors throughout Indonesia. The exam used this year is the Minimum Competency Assessment (AKM). The implementation of AKM is also carried out by SD/MI. In dealing with AKM, MI Darussalam Karanganyar students must be able to operate a computer/laptop to be able to answer AKM questions, because AKM questions are based online and MI students are not yet able to use laptops/computers. Therefore, students held training and simulations for class 5 MI Darussalam students who would face AKM. The purpose of this training and simulation is to train students to be able to use laptops as well as to know Microsoft Word and how to type 5 fingers, because this is the most important capital so that future students can work on AKM questions. The method used is Training and Simulation. The results that can be obtained from this training are that students can operate Laptops, How to Login AKM, Answer AKM questions, Type 5 fingers and know the functions of the keyboard keys and Microsoft Word Toolbar. In addition, it gets the value of wanting to continue learning, honest, enthusiastic, communicative, interesting.
\end{abstract}

Keyword : Typing, Microsoft Word, AKM

Submitted: Agustus 2021, Accepted: Agustus 2021, Published:Agustus 2021

ISSN 2746-6345(media online) 


\section{PENDAHULUAN}

Mendikbud telah menyiapkan pengganti UN yang disebut Asesmen Kompetensi Minimum dan Survei Karakter (AKM \& SK). Perencanaan program AKM dan SK ini tentu menjadi tantangan tersendiri bagi para guru. Terlebih AKM dan SK ini bisa dikatakan sebagai 'barang' baru yang harus dihadirkan dengan tiga hal, yakni literasi, numerasi dan sains. Bukan hanya pihak guru yang cepat adaptasi, namun juga siswa, orang tua dan para stakeholder. Menteri pendidikan di Indonesia pada masa abad 21 melakukan perubahan dalam ujian nasional dengan Asesmen Nasional yaitu yang terdiri dari tigas bagian 1) Asesmen Kompetensi Minimum (AKM) ; 2) Survei Karakter; 3) Survei Lingkungan (Pendidikan, 2019) Konten numerasi dalam AKM terdiri dari : bilangan, geometri data pengukuran, aljabar, data dan ketidakpastian (Kemdikbud, 2020). (AKM) merupakan penilaian kompetensi mendasar yang diperlukan oleh semua murid untuk mampu mengembangkan kapasitas diri dan berpartisipasi positif pada masyarakat (Kemdikbud, 2020).Kementrian dan kebudayaan selanjutnya mengeluarkan kebijakan baru sebagai pengganti UN yaitu melalui Assesmen Kemampuan Nasional (AKM).

Microsoft Word adalah aplikasi pengolah kata yang sangat populer pada saat ini, dengan aplikasi tersebut dapat memudahkan kerja manusia, salah satunya dalam membuat artikel. Kegiatan pengabdian pada masyarakat dititik beratkan dalam bentuk pelatihan tentang cara menggunakan Laptop dan pelatihan dasar Microsoft Word bagi siswa siswi kelas 5 MI Darussalam Karanganyar.pengoprasian Microsoft Word dengan mudah dan cepat. Materi yang disampaikan pada pembelajaran ini adalah antara lain : Materi Dasar Komputer, Pengenalan Microsoft Word 2007. Microsoft Word merupakan salah satu produk dari microsoft yang merupakan aplikasi pengolah kata yang memiliki banyak keunggulan dibandingkan dengan sofware lain yang samasama membidangi olah kata.Diharapkan dengan adanya pelatihan tersebut, siswa-siswi dapat lebih mengetahui tentang penggunaan Laptop dan Microsoft Word dengan setiap fungsi masingmasing tombol yang ada di Laptop pada bagian Microsoft Word, sehingga dapat membantu saat pengerjaan soal-soal AKM (Asesmen Kompetensi Minimum) yang diantara-Nya soal-soal Literasi, Numerasi, maupun meningkatkan kreativitas siswa siswi kelas 5 MI Darussalam Karanganyar. Kemampuan numerasi dapat diartikan sebagai kemampuan seseorang untuk merumuskan, menerapkan, dan menafsirkan matematika berbagai konteks, termasuk kemampuan melakukan penalaran secara amatis, dan menggunakan konsep, prosedur dan fakta untuk menggambarkan, menjelaskan atau memperkirakan fenomena/kejadian (Ekowati et al., 2019). Asesmen Kompetensi Minimum (AKM) dan Survei Karakter merupakan salah satu kebijakan merdeka belajar yang digagas oleh Mendikbud yang ditujukan untuk meningkatkan mutu pendidikan di Indonesia.

latihan pengetikan dapat dilanjutkan dengan level WORD dimulai dari WORD A-Z. Hal yang dapat dilakukan adalah dengan menghafalkan kembali letak/posisi huruf yang ada pada keyboard dan terus melatih keterampilan mengetik. Latihan pengetikan 5 jari yaitu pengetikan yang dilakukan dengan menggunakan kedua tangan kanan dan kiri dengan setiap jari-jari yang digunakan hanya 5 jari. Untuk dapat mengerjakan soal-soal AKM siswa siswi MI Darussalam Karanganyar harus bisa mengetahui dasar-dasar komputer dan cara mengetik. Masalah yang dihadapi pada MI Darussalam, siswa belum pernah bermain laptop sehingga pada kesempatan pelatihan ini dapat diajarkan tentang cara mengetik. Asesmen Kompetensi Minimum (AKM) mengukur literasi membaca dan literasi matematika (numerasi) peserta didik

Hasil dari kegiatan pengabdian yang dilaksanakan memberikan pengalaman dan ketrampilan pada para siswa MI Darussalam Karanganyar dalam mengoperasikan Laptop dan menggunakan Microsoft Word. Dengan demikian, pelaksanaan kegiatan pengabdian kepada masyarakat dengan judul "Pelatihan penggunaan Microsoft Word dalam persiapan AKM Siswa kelas V MI Darussalam Karanganyar" sehingga dapat memberikan manfaat yang signifikan bagi peningkatan keterampilan dan pengetahuan siswa siswi dalam memanfaatkan teknologi informasi dan komputer, khususnya untuk melaksanakan Program Mendikbud AKM (Asesmen Kompetensi 
Minimum). Kegiatan yang dilaksanakan berupa pendampingan dalam bentuk pelatihan menggunakan Microsoft Word pengenalan siswa kelas 5 MI Darussalam untuk persiapan menghadapi AKM. Materi pelatihan disesuaikan dengan kebutuhan siswa kelas 5 MI Darussalam yang menunjang pada proses pelaksanaan program Mendikbud yaitu AKM.

\section{METODE PELAKSANAAN}

Metode pelaksanaan yang digunakan dalam Pengabdian Masyarakat ini terdapat beberapa pembahasan diantaranya yaitu Sasaran Pengabdian Masyarakat, Tahapan Pelaksanaan Pengabdian Masyarakat dan Proses Pengabdian Masyarakat dan Teknis Analysis.

\section{Sasaran Pengabdian Masyarakat}

Objek Pengabdian Masyarakat ini yaitu Siswa kelas 5 MI Darussalam Karanganyar, yang merupakan siswa atau peserta yang akan melaksanakan kegiatan program Mendikbud AKM (Asesmen Kompetensi Minimum) yang dilaksanakan dengan menggunakan media Teknologi dan Informasi.

Pelaksanaan Pengabdian Masyarakat ini melibatkan beberapa pihak diantaranya, Kepala Sekolah, Guru dan Orang tua siswa kelas 5 MI Darussalam. Dari beberapa pihak tersebut yang nantinya dapat menyukseskan kegiatan pengabdian masyarakat ini dan program Mendikbud.

\section{Tahapan Pelaksanaan Pengabdian Masyarakat}

Dengan adanya program Mendikbud yaitu AKM (Asesmen Kompetensi Minimum) menjadi suatu tugas juga bagi para Guru MI Darussalam untuk mengadakan pelatihan kepada Siswa yang akan mengikuti Program AKM melalui media Teknologi Informasi atau menggunakan Laptop. berikut.

Pada permasalahan tersebut, dapat diselesaikan dengan beberapa tahapan yaitu sebagai

a. Pada tahapan pertama, mahasiswa pengabdian melakukan beberapa kegiatan, di antaranya koordinasi para pelaksana untuk menyiapkan tempat dan perlengkapan guna mendukung terlaksananya pelatihan, kemudian mahasiswa pengabdian melakukan koordinasi dengan para peserta yaitu guru dan siswa siswi kelas 5 MI Darussalam Karanganyar untuk pelaksanaan pendampingan.

b. Langkah kedua mempersiapkan Buku Pegangan pelatihan penggunaan Microsoft Word untuk persiapan program Mendikbud AKM bagi siswa siswi kelas 5 dengan rincian materi/buku panduan soal-soal AKM seperti yang terlihat pada Gambar 1 di bawah. 


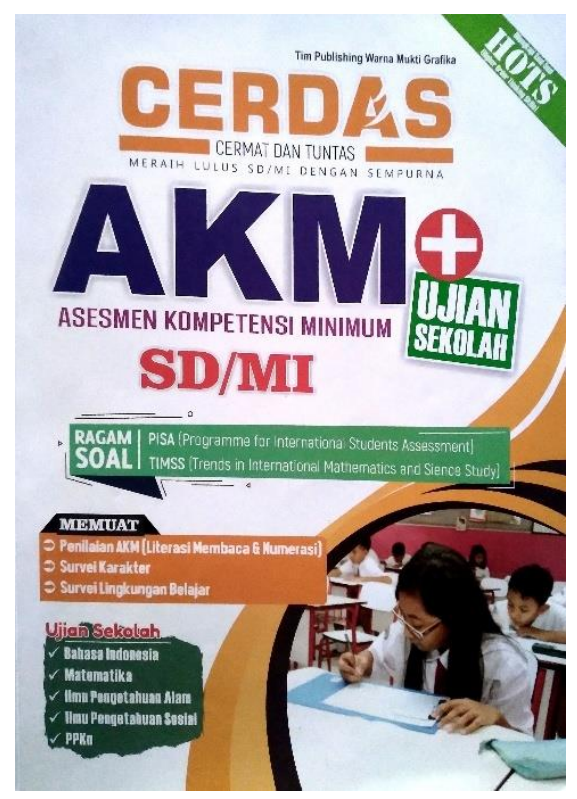

Gambar 1. Buku panduan AKM

Untuk mengukur tingkat keberhasilan kegiatan pendampingan pelatihan penggunaan Microsoft Word dalam persiapan menghadapi pelaksanaan Program Mendikbud AKM bagi siswa siswi kelas 5 MI Darussalam ini, peserta diberikan latihan untuk membuat dan mengetik nama sendiri dan belajar mengenal bagian-bagian pada Microsoft Word serta pengenalan tombol-tombol di keyboard. Tahap ini dimaksudkan untuk mengetahui kemampuan para siswa dalam mengoperasikan Laptop yang diajarkan untuk mengerjakan soal-soal AKM

c. Langkah ketiga yaitu diadakan pelatihan Pengenalan Microsoft Word pada siswa siswi kelas 5 MI Darussalam, yang merupakan sebagai salah satu pengenalan cara mengetik, mengenal fungsi tombol yang ada pada laptop dan toolbar pada Microsoft Word sehingga pada saat simulasi siswa sudah ada pemahaman dasar. Seperti pada Gambar 2 di bawah ini.

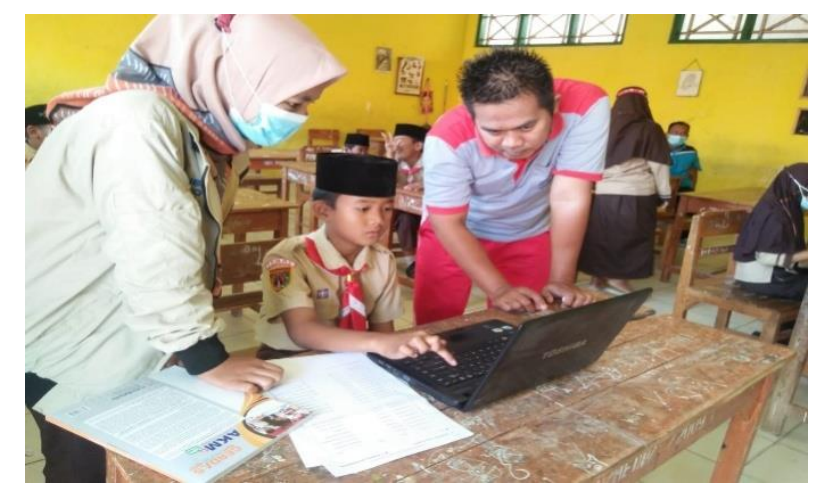

Gambar 2. Pengenalan Microsoft Word

d. Langkah keempat yaitu diadakan adanya Simulasi Literasi ke 1, pada kegiatan Simulasi ini siswa siswi kelas 5 dibagi menjadi beberapa kelompok, karena keterbatasan Laptop dan mengikuti protokol kesehatan. Pada Simulasi ke 1, siswa siswi kelas 5 MI Darussalam dilatih atau dibimbing untuk cara Login pada Website https://hasilun.puspendik.kemdikbud.go.id 
dan pengenalan cara menjawab soal pada AKM. Seperti yang terlihat pada gambar 3 di bawah.

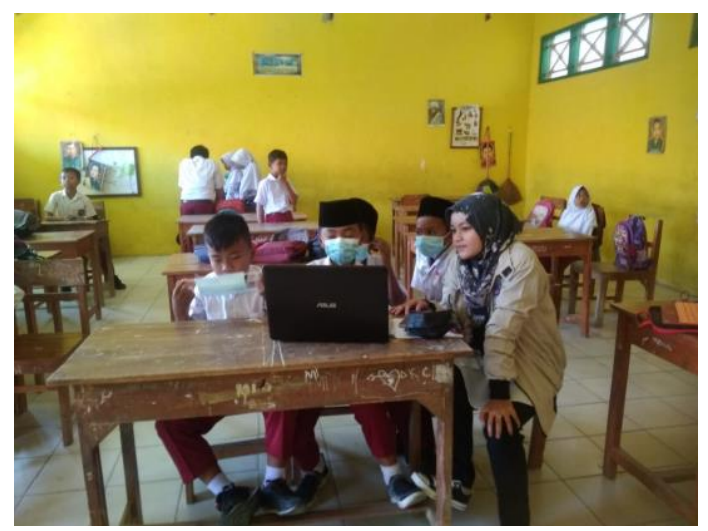

Gambar 3. Simulasi ke 1

e. Langkah kelima yaitu diadakan adanya Simulasi Literasi ke 2 pada kelompok 2, pada Simulasi ke 2 siswa MI Darussalam Karanganyar dilatih atau dibimbing untuk cara Login seperti pada Simulasi ke 2.

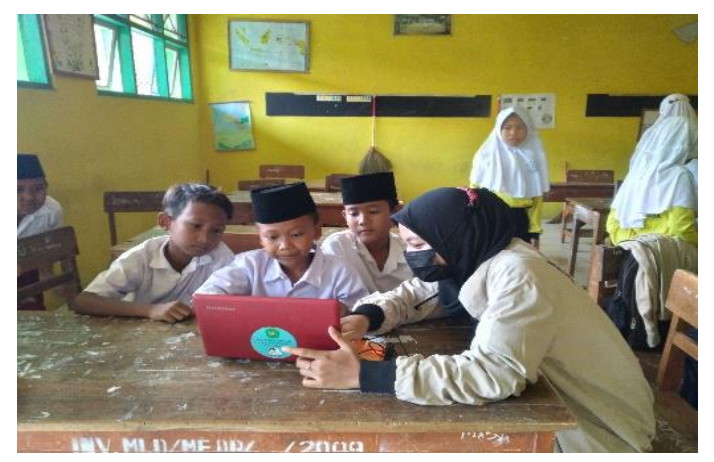

Gambar 2. Simulasi ke 2

f. Langkah keenam yaitu pelaksanaan Simulasi Numerasi ke 3 pada kelompok 1 siswa kelas 5 MI Darussalam Karanganyar, Pada simulasi ke 3, siswa dilatih menjawab soal-soal Numerasi atau soal-soal matematika dan cara menjawabnya.

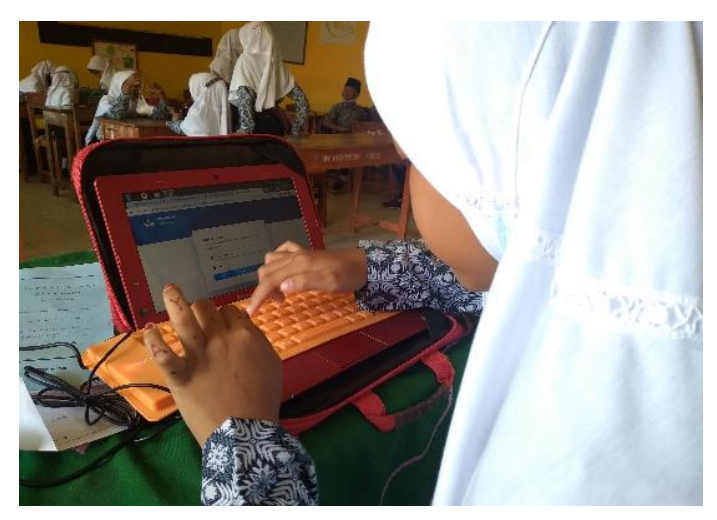

Gambar 3. Simulasi ke 3 
g. Langkah ketujuh yaitu pelaksanaan Simulasi Numerasi ke 4 pada kelompok 2, pada Simulasi ke 4 ini siswa siswi dilatih untuk Login dan menjawab soal-soal Numerasi atau matematika beserta cara-cara menjawab soalnya pada web AKM.

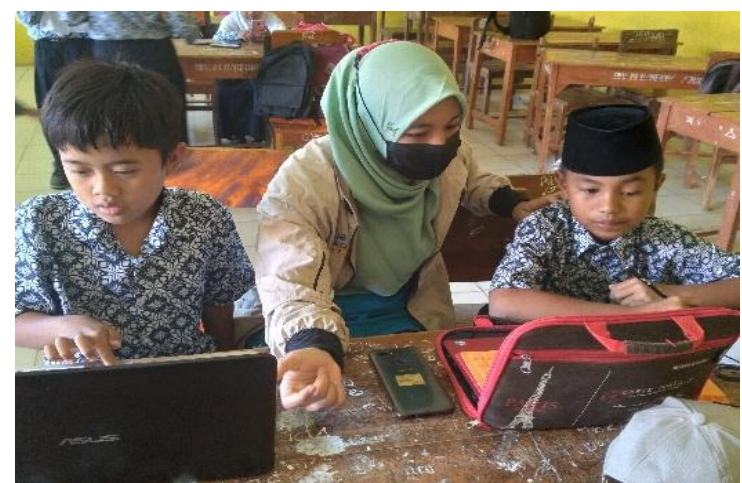

Gambar 4. Simulasi ke 4

h. Langkah ke delapan yaitu pelaksanaan Simulasi Numerasi dan Literasi pada siswa siswi kelas 5 MI Darussalam Karanganyar, pada simulasi ini siswa menjawab soal dengan teman sebangkunya dengan arahan atau bimbingan dari Mahasiswa .

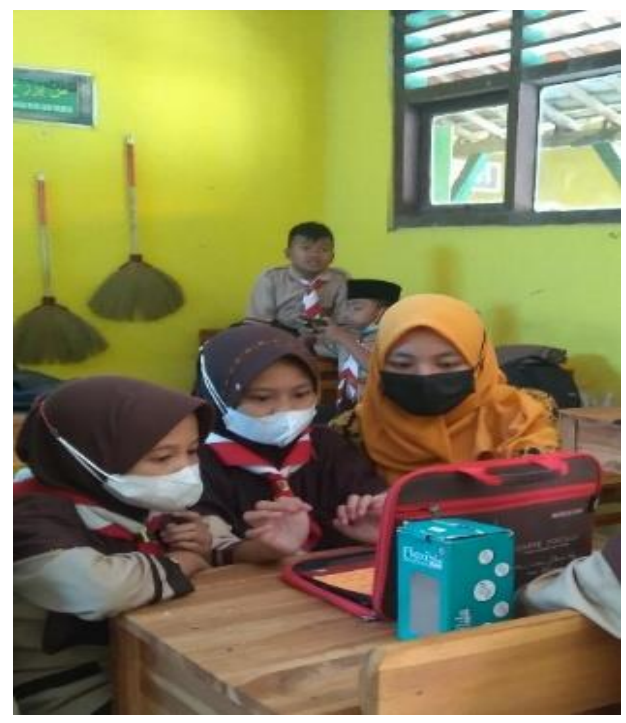

Gambar 5. Simulasi ke 5

\section{HASIL DAN PEMBAHASAN}

Hasil Pengabdian Masyarakat ini yaitu, siswa siswi kelas 5 MI Darussalam mulai bisa mengetik di Microsoft Word dengan 5 jari, di mana jari manis kiri berada di Caps Lock, jempol kanan berada di bagian Space, Jempol kiri dibagian Touchpad untuk mengarahkan Kursor pada Layar/Monitor, dan kedua jari kanan berada di posisi huruf. Pada Langkah pertama siswa dikenalkan terlebih dahulu mengenai bagian-bagian di Microsoft Word seperti Pengetahuan umum siswa siswi tentang tombol-tombol keyboard, Pengetahuan siswa siswi tentang posisi dan letak tombol pada keyboard, Pengetahuan siswa siswi terhadap teknik pengetikan 5 jari, kemudian pada Tahap Simulasi siswa siswi kelas 5 di berikan bimbingan/pelatihan tentang bagaimana cara Login pada akun AKM dan juga cara menjawabnya. Kemudian pada Simulasi Akhir siswa siswi 
dilatih untuk Login sendiri dan menjawab soal-soal pada Website AKM untuk dapat melihat perkembangan/progress siswa siswi kelas 5 MI Darussalam Karanganyar. Tabel tahap kegiatan dapat ditunjukkan Tabel 1.

\section{Tabel 1. Tahap Kegiatan}

\section{No Tahap Kegiatan \\ 1. Mahasiswa melakukan penyampaian materi tentang Pengetikan di Microsoft Word langsung dipraktikan didepan siswa siswi kelas 5 dan Mengenalkan bagian-bagian yan g ada pada Microsft Word seperti : Font, Ukuran Huruf, Bold,Italic, dan bagian yang ada di Keyboard : Caps Lock, Space, Back Space, Enter, Shift, Kursor dan sebagainya.}

2. Mahasiswa menyediakan Laptop, Wifi, yang akan digunakan untuk Pelatihan Mengetik 5 Jari untuk persiapan AKM

3. Mahasiswa mengadakan Pelatihan Mengetik 5 Jari secara satu persatu

4. Mahasiswa mengadakan Simulasi tentang cara Login dan menjawab soalsoal AKM.

\section{Tujuan yang di Capai}

Siswa dapat mengenal tentang Dasardasar pada Microsoft Word dan mengenal dasar-dasar yang ada pada Keyboard.
Siswa dapat melakukan praktek secara langsung dengan menggunakan Laptop.

Siswa dapat mengetik dan memahami tentang fungsi tombol-tombol pada keyboard dan pada bagian Micosoft Word. Siswa bisa melakukan Login pada AKM secara mandiri dan mengetahui soal-soal AKM dan cara menjawabnya.

Pada pelaksanaan tahap kegiatan yang pertama-tama adalah mengenalkan kepada siswa siswi kelas 5 tentang Microsoft Word, bahwasanya untuk bisa menulis sesuatu bisa menggunakan Microsoft Word. Dan juga mengenalkan bagian-bagian Toolbar yang ada pada Microsoft Word dan mengenalkan bagian tombol yang ada pada keyboard beserta fungsinya. Tabel 2 dapat menunjukkan jadwal kegiatan.

Tabel 2. Jadwal Kegiatan

\begin{tabular}{|c|c|c|c|c|c|c|c|c|}
\hline \multirow[t]{2}{*}{ NO. } & \multirow[t]{2}{*}{ Jenis Kegiatan } & \multicolumn{7}{|c|}{ September } \\
\hline & & 4 & 6 & 7 & 8 & 9 & 10 & 11 \\
\hline 1 & $\begin{array}{l}\text { Penyampaian materi dan praktek } \\
\text { langsung }\end{array}$ & $\sqrt{ }$ & & & & & & \\
\hline 2 & $\begin{array}{l}\text { Pengetikan yang dilakukan siswa } \\
\text { dengan pendampingan Mahasiswa }\end{array}$ & & $\sqrt{ }$ & & & & & \\
\hline 3 & $\begin{array}{l}\text { Simulasi } 1 \text { cara Login dan Mengetik } 5 \\
\text { jari }\end{array}$ & & & $\sqrt{ }$ & & & & \\
\hline 4 & $\begin{array}{l}\text { Simulasi } 2 \text { Login dan mengerjakan soal- } \\
\text { soal Literasi }\end{array}$ & & & & $\sqrt{ }$ & & & \\
\hline 5 & $\begin{array}{l}\text { Simulai } 3 \text { dan mengerjakan soal-soal } \\
\text { Numerasi }\end{array}$ & & & & & $\sqrt{ }$ & & \\
\hline 6 & $\begin{array}{l}\text { Simulasi } 4 \text { dan mengerjakan soal-soal } \\
\text { Numerasi }\end{array}$ & & & & & & $\sqrt{ }$ & \\
\hline 7 & $\begin{array}{l}\text { Simulasi } 4 \text { dan mengerjakan soal-soal } \\
\text { Numerasi dan Literasi }\end{array}$ & & & & & & & $\sqrt{ }$ \\
\hline
\end{tabular}


Untuk dihari berikutnya, Mahasiswa mengadakan Simulasi dengan pendamping atau pelatih Simulasi tersebut adalah Mahasiswa dan Simulasi diadakan selama 7 Hari.

Selama 7 hari Simulasi siswa siswi kelas 5 boleh untuk memilih Literasi atau Numerasi atau keduanya, dan juga siswa dikenalkan tentang cara Login pada Website AKM, kemudian mengajarkan kepada siswa siswi bagaimana cara Login.

Simulasi tersebut di fokuskan agar siswa siswi kelas 5 MI Darussalam mengenal dan bisa mengetik dengan variasi 5 jari dan juga cara Login. Karena tahap utama dalam mempersiapkan AKM adalah dimana siswa siswi bisa mengoperasikan Laptop, dan untuk mengerjakan soal-soal pada AKM itu urusan nanti setelah siswa siswi sudah bisa Login dan Mengetik sendiri dan cara menjawab soal sendiri. Selama Simulasi Mahasiswa juga menanyakan kepada siswa siswi apakah sudah bisa mengetahui fungsi-fungsi pada keyboard, dan apakah sudah bisa mengetik dengan 5 jari dan apakah siswa siswi sudah tahu caranya Login pada AKM dan memilih atau mengganti menjawab soal-soal AKM.

Dengan adanya Simulasi selama 7 hari siswa siswi kelas 5 dapat: Mengetahui bagian Toolbar pada Microsoft Word, Mengetahui fungsi pada Keyboard, bisa Login pada Website AKM, Bisa mengetahui bahwa soal pilihan ganda, pilihan ganda kompleks, menjodohkan, isian singkat dan uraian dan bentuk soalnya dan cara menjawabnya , baik pada soal-soal Literasi dan Numerasi.

\section{KESIMPULAN}

Dari pembahasan yang telah diuraikan diatas, dapat disimpulkan bahwa dengan adanya Mahasiswa yang melaksanakan Pengabdian di MI Darussalam, dapat membantu Guru dalam mengajarkan dasar-dasar komputer dan dasar-dasar pada Microsoft Woord untuk persiapan menghadapi AKM. Mahasiswa mengajarkan bagian dan tombol pada Laptop dan Microsoft Word dengan mengadakan Simulasi selama 7 hari atau seminggu, jumlah keseluruhan siswa siswi kelas 5 yaitu sebanyak 42 siswa laki-laki 27, dan siswa perempuan 15. Dari 42 siswa siswi kelas 5 untuk keseluruhan sudah mengikuti Simulasi dan sudah bisa mengetik dan sudah mengetahui fungsi tombol atau bagian-bagian yang ada pada Microsoft Word dan Laptop. Dan untuk variasi mengetik dengan 5 jari hanya ada beberapa siswa siswi yang bisa melakukanya, karena sebagian dari siswa siswi kebanyakan belum pernah mengoperasikan Laptop sehingga siswa siswi perlu latihan terus menerus agar terbiasa dalam mengetik 5 jari.

\section{DAFTAR PUSTAKA}

Aisah, H., Zaqiah, Q. Y., Supiana, A., Islam, U., Sunan, N., \& Djati, G. (2021). Jurnal Pendidikan Islam Al-Affan. 1(2), 128-135.

Ap, K. X., Muhammadiyah, S. M. K., Setyaningsih, L. H., Muhsin, D., \& Si, M. (2013). Peningkatan Keterampilan Mengetik Sistem 10 Jari Buta Dengan Menggunakan Model Pembelajaran Berbasis Komputer Berbantu Media Typing Master Pada Siswa Kelas X Ap Smk Muhammadiyah 01 Pati. Economic Education Analysis Journal, 3(1), 89-93.

Cahyanovianty, A. D. (2020). Analisis Kemampan Numerasi Peserta Didik Kelas VIII dalam Menyelesaikan Soal Asesmen Kompetensi Minimum. Jurnal Cendekia: Jurnal Pendidikan Matematika, 05(02), 1439-1448.

Pascasarjana, P. (2012). Program pascasarjana. 2012.

Rokhim, D. A., Rahayu, B. N., Alfiah, L. N., Peni, R., Wahyudi, B., Wahyudi, A., Widarti, H. R., \& Malang, U. N. (2021). Analisis Kesiapan Peserta Didik Dan Guru Pada Asesmen Nasional ( Asesmen Kompetensi Minimum, Survey Karakter, Dan Survey Lingkungan Belajar ). 
Jurnal Administrasi Dan Manajemen Pendidikan, 4, 61-71.

Sulastri, T. (2014). Analisis Mengetik Cepat 10 Jari Menggunakan Teknologi Komputer Berbasis Aplikasi Software Rapidtyping. Jurnal LPKIA, 4(2), 13-18.

Wijayanto, M. A., Rizky, M., \& Iklil, M. A. (2019). Pelatihan Dasar Komputer Mengoperasikan Microsoft Word Dan Microsoft Excel Di Desa Sumberjati. 127-132.

Yuliandari, R. N., \& Hadi, S. (2020). Implikasi Asesmen Kompetensi Minimum dan Survei Karakter Terhadap Pengelolaan Pembelajaran SD. Jurnal Kependidikan Dasar Islam Berbasis Sains, 5(2), 203-219.

Widagda, Rachmawati Kusuma., Safitri, Ririn., Purwaningsih, Dian., Zunfradoh, Siti., Kanugrahan, Herbayu Ragil., Permatasari, Okadita., Maulida, Annisa., Santoso, Budi., Ihsanuddin, Catur., Alfian, Novianda., Handayani, Wahyu Tri. 2020. Cerdas Akm + US SD/M I. Boyolali : PT. Warna Mukti Grafika. 